\title{
Screening cystoscopy in chronically catheterized spinal cord injury patients
}

\author{
CC Yang ${ }^{1,2}$ and DE Clowers ${ }^{1}$ \\ ${ }^{1}$ Spinal Cord Injury Unit, Veterans Affairs Puget Sound Health Care System, Seattle, Washington; ${ }^{2}$ Department of \\ Urology, University of Washington, Seattle, Washington, USA
}

Study design: Retrospective review.

Objectives: An annual screening cystoscopy protocol was begun at our institution in an attempt to minimize the morbidity and mortality of bladder cancer in the chronically catheterized spinal cord injured (SCI) population. The objectives of this study are: (1) to present the results of 6 years of screening for primary bladder cancer in this population, and (2) examine the suitability of this protocol based upon accepted principles of cancer screening. Setting: Veterans hospital, Seattle, WA, USA.

Methods: SCI patients selected for screening cystoscopy were those who had been continuously catheterized for 10 or more years, or were smokers who had been catheterized for 5 or more years. Biopsies and/or urine cytologies were taken at the surgeon's discretion. Results: Fifty-nine patients underwent 156 cystoscopy procedures from January 1992 through December 1997. The vast majority of patients were at risk for autonomic dysreflexia, so cystoscopy was performed with anesthesia. No bladder cancers were diagnosed by screening cystoscopy. All bladder biopsies and cytology specimens were benign. During the same period of time four SCI patients presented with symptomatic bladder cancers. Two patients did not fit the criteria for surveillance, one patient was not being followed by the SCI unit and presented to an outside physician, and one patient had a screening cystoscopy 4 months prior to presenting with bladder cancer.

Conclusions: Cystoscopy does not fulfil the accepted criteria for screening for primary bladder cancer in SCI patients. The disease does not appear to be amenable to screening, the population to be screened is not easily definable, and the costs are excessive compared to the low cancer detection rate.

Keywords: spinal cord injury; bladder cancer; cystoscopy; cancer screening

\section{Introduction}

Spinal cord injured (SCI) patients are reported to have a higher incidence of bladder cancer compared to the general population. ${ }^{1,2}$ Factors thought to be associated with this higher incidence include chronic, indwelling catheterization, recurrent infections, and bladder stone formation. Screening in patients with long-standing SCI has been reported to be helpful in identifying bladder malignancies in otherwise asymptomatic persons. ${ }^{3}$ A screening protocol was instituted in January 1992 at our institution requiring annual cystoscopy to be performed on SCI patients deemed at high risk for the development of bladder cancer. The results of this 6 year screening protocol are reported here, along with discussion of its efficacy and suitability.

Correspondence: C Yang, Urology Section 112U, Veterans Affairs Puget Sound Health Care System - Seattle Division, 1660 South Columbian Way, Seattle, Washington 98108-1597, USA

\section{Methods}

Five hundred SCI patients are followed by a comprehensive annual health maintenance evaluation at the Veteran's Affairs Puget Sound Health Care System Spinal Cord Injury Unit. The yearly urologic evaluation includes a urinalysis and urine culture, renal ultrasound and KUB on every patient. Cystoscopy was performed on patients who were continuously catheterized for 10 or more years, or were smokers and catheterized for 5 or more years.

A retrospective review of the screening cystoscopies performed on SCI patients over a 6 year period was performed. The large majority of these cystoscopies were performed on quadriplegic patients who were at risk for autonomic dysreflexia, so these procedures were performed in the operating room with a spinal anesthetic. Bladder biopsies and/or urine cytologies were taken at the surgeon's discretion. Biopsies were taken for abnormal appearing lesions, and urine for cytology was taken at the start of the procedure. The decision to perform a biopsy or send urine for 
cytologic examination was left to the attending physician at the time of cystoscopy. Screening cystoscopies did not include those procedures performed for a particular indication, eg, hematuria or recurrent urinary tract infections.

\section{Results}

From January 1992 through December 1997, 156 screening cystoscopies were performed on 59 individual patients. Two of these patients were female. The number of cystoscopies per individual during this period was variable (Table 1). Over half of the cohort

Table 1 Number of screening cystoscopies performed per patient, over 6 year period (1992 through 1997)

\begin{tabular}{lc}
\hline Number performed & Number of patients \\
\hline 1 & 19 \\
2 & 13 \\
3 & 6 \\
4 & 13 \\
5 & 7 \\
6 & 1 \\
\hline
\end{tabular}

Table 2 Annual number of screening cystoscopies

\begin{tabular}{lc}
\hline Year & Number \\
\hline 1992 & 27 \\
1993 & 30 \\
1994 & 25 \\
1995 & 28 \\
1996 & 21 \\
1997 & 25 \\
\hline
\end{tabular}

(32 out of 59) had only one or two cystoscopic examinations over the course of 6 years. The average annual number of procedures was 26 (Table 2).

Ninety-three bladder biopsies and 18 urine cytologies were obtained, none of which demonstrated malignant changes. No bladder cancers were diagnosed through screening. The only complications were transient post-operative hematuria, with one patient requiring readmission for clot retention. There were no anesthetic-related complications.

During the same 6 year period, four SCI patients were diagnosed at our hospital with bladder cancer (three transitional cell carcinoma, one squamous cell carcinoma). All had symptoms at presentation and were diagnosed outside of the surveillance protocol (Table 3). One patient (JW) had undergone an annual evaluation cystoscopy with biopsy 4 months prior to presentation, without abnormal findings. Two patients were being followed for annual health maintenance, but did not wear a catheter for urine damage, and thus were not on the surveillance protocol. One patient was referred to us from an out-of-town physician. No further bladder cancers in SCI patients have been diagnosed since 1994.

\section{Discussion}

Screening for cancer is a means of accomplishing early detection of disease in a large number of asymptomatic people, to reduce the complications and mortality rate from that cancer among the persons screened. The following characteristics make particular cancers more suitable than others for screening: ${ }^{4,5}$ (a) substantial morbidity and mortality, (b) a high prevalence in a detectable preclinical state, (c) the possibility of effective and improved treatment because of early detection, and (d) the availability of a good screening test. The screening test must be safe, rapid, inexpen-

Table 3 Bladder cancer in SCI patients 1992-1997

\begin{tabular}{|c|c|c|c|c|c|c|c|c|}
\hline Patient & $\begin{array}{l}\text { Age at } \\
d x\end{array}$ & $\begin{array}{l}\text { Level of } \\
\text { SCI }\end{array}$ & $\begin{array}{l}\text { Years } \\
\text { injured }\end{array}$ & Risk factors & Presentation & Treatment & Pathology & Outcome \\
\hline DS & 68 & $\begin{array}{l}\text { C5 complete } \\
\text { quadriplegia }\end{array}$ & 18 & $\begin{array}{l}\text { Smoker } \\
\text { bladder stones }\end{array}$ & $\begin{array}{l}\text { Bladder stones } \\
\text { hematuria }\end{array}$ & $\begin{array}{l}\text { Cystectomy } \\
\text { ileal conduit }\end{array}$ & $\begin{array}{l}\text { Grade } 3 / 3 \\
\text { TCCa } \\
\text { T3N0M0 }\end{array}$ & $\begin{array}{l}\text { Disease free at } \\
5 \text { years }\end{array}$ \\
\hline JW & 60 & $\begin{array}{l}\text { C6 complete } \\
\text { quadriplegia }\end{array}$ & 5 & $\begin{array}{l}\text { Smoker } \\
\text { chronic catheter }\end{array}$ & $\begin{array}{l}\text { Incidental } \\
\text { finding on } \\
\text { cystoscopy for } \\
\text { renal stones }\end{array}$ & $\begin{array}{l}\text { Cystectomy } \\
\text { ileal conduit }\end{array}$ & $\begin{array}{l}\text { Grade } 3 / 3 \\
\text { TCCa } \\
\text { T3N1M0 }\end{array}$ & $\begin{array}{c}\text { Dead } 11 \text { months } \\
\text { post diagnosis } \\
\text { of metastases }\end{array}$ \\
\hline $\mathrm{JC}$ & 63 & $\begin{array}{l}\text { C5 partial } \\
\text { quadriplegia } \\
\text { (Brown-Sequard) }\end{array}$ & 4 & Smoker & Gross hematuria & $\begin{array}{l}\text { TURBT, } \\
\text { palliative } \\
\text { radiation }\end{array}$ & $\begin{array}{l}\text { Grade } 3 / 3 \\
\text { TCCa } \\
\text { T3bN2M0 by } \\
\text { CT scan }\end{array}$ & $\begin{array}{l}\text { Dead } 5 \text { months } \\
\text { post diagnosis }\end{array}$ \\
\hline RW & 56 & $\begin{array}{l}\mathrm{T} 10 \text { complete } \\
\text { paraplegia }\end{array}$ & 35 & $\begin{array}{l}\text { Chronic catheter } \\
\text { bladder stones }\end{array}$ & Pyelonephritis & $\begin{array}{l}\text { Cystectomy } \\
\text { ileal conduit }\end{array}$ & $\begin{array}{l}\text { Grade } 3 / 3 \\
\text { SCCa } \\
\text { T3cN0M0 }\end{array}$ & $\begin{array}{l}\text { Disease free at } \\
3.5 \text { years }\end{array}$ \\
\hline
\end{tabular}

$\mathrm{TURBT}=$ transurethral resection of bladder tumor; $\mathrm{TCCa}=$ transitional cell carcinoma; $\mathrm{SCCa}=$ squamous cell carcinoma 
sive, easy to apply and reproducible. It must also be valid, of adequate sensitivity, specificity and predictive value. ${ }^{5,6}$ These criteria are generally accepted by the medical community as reasonable measures on which to institute cancer screening.

Using these criteria, screening cystoscopy for the detection of bladder cancer is not justified in the chronically catheterized SCI population. The morbidity and mortality of this disease are substantial but the remaining criteria justifying screening in this cohort are not clearly met. Treating bladder cancer in earlier stages does confer a survival advantage. ${ }^{7}$ However, it is not apparent whether there is an identifiable preclinical state that if detected and treated would effect the outcome of most patients. Stonehill et al reported the development of symptomatic bladder cancer in SCI patients despite their participating in a screening cystoscopy protocol, ${ }^{8}$ an occurrence which was noted in this study as well. This suggests that lowstage disease is not readily identified by screening. The majority of the reported cases of bladder cancer in SCI patients list the tumor stage at the time of diagnosis as T2 or greater, with very few superficial tumors. ${ }^{3,8,9}$ The high stage of the disease at diagnoses would argue for heightened surveillance. But the rapidly progressive nature of the disease, seen in two patients during this study who died within a year of diagnosis and reported by others, ${ }^{10,11}$ discounts the utility of practical screening measures.

Cystoscopy is the gold standard by which to diagnose bladder cancer, but its efficacy as a diagnostic tool does not translate into an efficient and cost-effective screening device. ${ }^{4}$ The present method of screening does not justify the cost and potential risks of the procedure. Cystoscopy as a screening mechanism in this study was generally safe, and there were no anesthetic complications. But the costs were significant, particularly when the procedure required the operating room and anesthesia, which in our study involved the majority of the patients. Other high risk, non-SCI populations, such as long standing smokers or men with exposure to occupational bladder cancer carcinogens, are not recommended for routine screening cystoscopy due to the invasiveness of the test. $^{12}$

Our protocol did not include two patients who developed bladder cancer because they were not considered to be 'high risk', ie did not use catheter drainage. To achieve adequate sensitivity, the screening would have to encompass nearly all SCI patients, regardless of their catheter status and length of injury. Performing annual cystoscopies on all SCI patients would be difficult to conduct in a timely and costefficient manner.

Ease of application is one of the criteria for an effective screening test. A large number of patients had only one or two cystoscopies over the course of 6 years, which meant these patients had 'spot-checks', rather than being part of a true annual surveillance protocol. Reasons for this were that some patients were newly enrolled in the SCI system while others were lost to follow-up after initial evaluation. Other patients declined the procedure because of its invasiveness and the need for hospitalization and anesthesia. The difficulty in scheduling patients makes cystoscopy less attractive as a screening measure.

Possible alternatives to screening cystoscopy exist, but their value in SCI patients is equivocal or unproved. For use in the general population, the following tests are typically meant to be used in conjunction with cystoscopy for the diagnosis of bladder cancer, not in place of it. Urine cytology has been used in screening for bladder cancer in cohorts of men exposed to occupational bladder carcinogens, but did not have a clinical impact on the development of cancer. ${ }^{13}$ A recent study by Stonehill advocates the use of cytology for screening SCI patients, ${ }^{14}$ whereas other reports have shown that it is not adequately specific due to concurrent inflammation from infection and catheterization. ${ }^{2,15}$ In recent years, several assays have been introduced as screening mechanisms for recurrent bladder cancer, though none have been indicated for populations at risk without a prior bladder cancer diagnosis. The bladder tumor antigen test (BTA-Stat, Bard Diagnostic Sciences, Inc., Redmond, WA, USA) assays urine for a urothelial basement membrane protein that is released when bladder tumors are present. ${ }^{16}$ However, the test is falsely positive in the presence of urinary leukocytes, which are found in most chronically catheterized SCI patients. A fibrin degradation product assay is available for urine (AuraTek FDP, Per Immune Inc., Rockville, MD, USA), ${ }^{17}$ and if positive, is suggestive of recurrent bladder tumor. Similar to the BTA, FDP produced false positive results in the presence of inflammation, making this test inappropriate for SCI patients. Most bladder tumors will express hematuria at some point, though intermittently. ${ }^{12}$ Messing et al performed screening tests using hematuria chemical reagent strips in a large population of otherwise asymptomatic older men. ${ }^{18}$ Hematuria screening appeared to reduce bladder cancer mortality in this population. In SCI patients, particularly those that are chronically catheterized, urine consistently clear of hematuria may be difficult to achieve, thus rendering reagent strips useless for screening.

Although the annual incidence is fairly low, bladder cancer in SCI patients does occur more frequently than in the general population where approximately 50000 new cases are diagnosed in the USA each year. ${ }^{12}$ Earlier studies reported the annual incidence of bladder cancer in chronically catheterized SCI patients to be $8-10 \%{ }^{1,2}$ More recent reports quote a lower incidence of bladder cancer in this population, with a less than $1 \%$ incidence. ${ }^{9}$ However, comparison of actual incidence rates between studies is difficult, as some reports quote incidence rates among the total SCI cohort, others quote incidence rates from chronically catheterized SCI patients alone, and 
annual incidence rates are not calculated in all studies. Nonetheless, there does seem to be a recent decline in the incidence of bladder cancer, which our data supports. This may be attributable to a decrease in the number of patients with risk factors associated with bladder cancer development. The decrease has likely come about due to wider acceptance of clean intermittent catheterization as a method of bladder hygiene, and better recognition with earlier treatment of urinary tract infections and bladder stones. At our hospital, practitioners are particularly attentive to bladder hygiene in SCI patients. Patients are taught self-catheterization when feasible. Urinary tract infections are treated when patients are symptomatic, with a health care network that can be utilized to efficiently manage the diagnosis and treatment of these infections, even in remote areas of the referral base. With the declining incidence of bladder cancer, the need to provide screening becomes less a concern.

\section{Conclusion}

In this study, screening cystoscopy for primary bladder cancer in the chronically catheterized SCI population has not been shown to fulfil the criteria for cancer screening. There were no cancers detected by cystoscopy during 6 years of screening, while four cancers were diagnosed in SCI patients during the same time period. Although expanding the cohort of persons to be screened may increase the detection rate, the cost of screening cystoscopy, particularly with anesthesia, is excessive. The disease is not amenable to screening because of its rapidly progressive nature in a large portion of patients. The incidence of bladder cancer in SCI patients appears to be declining, which lessens the urgency for screening. Other screening measures have yet to be proven efficacious.

\section{Acknowledgements}

The authors gratefully acknowledge Brenda Kromm, RN for her assistance in this study.

\section{References}

1 Locke JR, Hill DE, Walzer Y. Incidence of squamous cell carcinoma in patients with long-term catheter drainage. $J$ Urol 1985; 133: $1034-1035$.

2 Kaufman JM et al. Bladder cancer and squamous metaplasia in spinal cord injury patients. J Urol 1977; 118: 967-971.

3 Navon JD, Soliman H, Khonsari F, Ahlering T. Screening cystoscopy and survival of spinal cord injured patients with squamous cell cancer of the baldder. J Urol 1997; 157: 21092111.

4 Rimer BK, Schildkraut J. Cancer Screening. In: DeVita VT, Hellman S, Rosenburg SA (eds). Cancer: principles \& practice of oncology, Fifth edition. Philadelphia: Lippincott-Raven Publishers 1997, pp 619-627.

5 Hulka BS. Cancer screening: Degrees of proof and practical application. Cancer 1988; 62: 1776-1780.

6 Wilson J, Junger G. Principles and practice of screening for disease. Public Health Papers 1968; 34: 7-151.

7 Frazier H, Robertson JE, Dodge RK, Paulson DF. The value of pathologic factors in predicting cancer-specific survival among patients treated with radical cystectomy for transitional cell carcinoma of the bladder and prostate. Cancer 1993; 71: 3993 4001 .

8 Stonehill WH, Dmochowski RR, Patterson AL, Cox CE. Risk factors for bladder tumors in spinal cord injury patients. $J$ Urol 1996; 155: $1248-1250$.

9 Bickel A, Culkin DJ, Wheeler JS. Bladder cancer in spinal cord injury patients. J Urol 1991; 146: $1240-1242$.

10 Yalla S. Editorial comment, Incidence of squamous cell carcinoma in patients with long-term catheter drainage. $J$ Urol 1985; 133: 1035

11 Broecker BH, Klein FA, Hackler RH. Cancer of the bladder in spinal cord injury patients. J Urol 1981; 125: 196-197.

12 Jonler M, Messing EM. Screening, early detection, and prevention of bladder tumors. In: Vogelzang N, Scardino PT, Shipley WU, Coffey DS (eds). Comprehensive Textbook of Genitourinary Oncology. Baltimore: Williams and Wilkins 1996, pp $351-358$

13 Cartwright R. Screening workers exposed to suspect bladder carcinogens. J Occup Med 1986; 28: 1017-1019.

14 Stonehill WH, Goldman HB, Dmochowski RR. The use of urine cytology for diagnosing bladder cancer in spinal cord injured patients. J Urol 1997; 157: $2112-2114$.

15 Bejany DE, Lockhart JL, Rhamy RK. Malignant vesical tumors following spinal cord injury. J Urol 1987; 138: $1390-1392$.

16 Sarosdy M et al. Results of a multicenter trial using the BTA test to monitor for and diagnose recurrent bladder cancers. J Urol 1995; 154: $379-384$

17 Johnston B, Morales A, Emerson L, Lundie M. Rapid detection of bladder cancer: a comparative study of point of care tests. $J$ Urol 1997; 158: $2098-2101$.

18 Messing E et al. Home screening for hematuria: results of a multiclinic study. J Urol 1992; 148: 289-292. 